\title{
Resveratrolün Staphylococcus Aereus, Escherichia Coli, Pseudomonas Aeruginosa ve Candida Albicans Üzerindeki Antibakteryel ve Antifungal Etkilerinin in Vitro olarak Değerlendirilmesi
}

\author{
Taner DAŞ*, Gülsüm DAŞ ${ }^{* *}$, Mahir KAPMAZ****
}

\section{Öz}

Amaç: Resveratrol, ilk olarak 1940 yılında Melanthiaceae (Dokuztepegiller) familyasında yer alan bitkinin köklerinden izole edilmiştir. Bitkilerde özellikle kırmızı üzüm, yer fıstığı, ananas, dut ve yaban mersininde yüksek konsantrasyonda bulunmaktadır. Resveratrol (3,5,4'trihidroksistilben) antioksidan, antifungal, antibakteriyel, anti-inflamatuar, anti-proliferatif etkilerin yanında çeşitli biyokimyasal etkilere sahip doğal bir polifenoldür. Bitkiler tarafından mikrobik, fungal ve fiziksel uyaranlara karşı üretilen antimikrobiyel ve antifungal etkili bir bileşik yani fitoaleksindir. Bu çalışmada Polygonum Cuspidatum kökünden elde edilen resveratrolün bazı mikrobik ve fungal insan enfeksiyonları üzerindeki çoğalmayı azaltıcı veya durdurucu etkisi olup olmadı̆̆ı araştırılmıştır.

Yöntem: Bu çalışmada Candida albicans, Escherichia coli, Pseudomonas aeruginosa ve Staphylococcus aureus mikroorganizmaları kullanılmıştır. Çalışmada kullanılan mikroorganizmaların her biri üremeleri için uygun besiyerlerine ekilmiştir. Her bir mikroorganizma biri normal şartlarda (resveratrol içermeyen) diğerleri ise $1 / 4$ ve $1 / 1$ dilüsyon oranlarında resveratrol içeren besiyerlerine ekilmiş ve organizmaların üremeleri için belirli sürelerde inkübasyona bırakılmıştır.

\footnotetext{
Özgün Araştırma Makalesi (Original Research Article)

Geliş / Received: 19.03.2019 \& Kabul / Accepted: 29.04.2019

${ }^{*}$ Uzm. Dr., Adli Tıp Kurumu, Morg İhtisas Dairesi Histopatoloji Şubesi, İstanbul, Türkiye, E-posta: tanerdas@hotmail.com ORCID ID https://orcid.org/o0oo-0002-1216-186X

** Dr., İstanbul Özel Yenibosna Safa Hastanesi, Kardiyoloji Kliniği, İstanbul, Türkiye, E-posta: gulsumdas@hotmail.com ORCIID ID https://orcid.org/o00o-0001-8457-3284 ${ }_{* * *}$ Dr., İstanbul Koç Üniversitesi Hastanesi, Enfeksiyon Hastalıkları ve Klinik Mikrobiyoloji, İstanbul, Türkiye, E-posta: mahirkapmaz@yahoo.com ORCID ID https://orcid.org/oooo0002-4115-3914
} 
Bulgular: Bu süre sonunda resveratrol içermeyen besiyerinde Staphylococcus aureus'un beta hemoliz ve üremesi saptanırken, $1 / 1$ ve $1 / 4$ dilüsyonlu resveratrol içeren \%5 koyun kanlı besiyerinde beta hemoliz yapma yeteneği kaybolmuş olup $1 / 1$ ve $1 / 4$ dilüsyonlu resveratrol içeren Mueller Hinton besiyerinde üremesi inhibe olmuştur. Resveratrol içermeyen ve içeren (1/1 ve 1/4 dilüsyonlu) besiyerlerinde Escherichia coli, Pseudomonas aeruginosa ve Candida albicans mikroorganizmalarının üremelerinde değişiklik saptanmamıştır.

Sonuç: Resveratrolün gram pozitif bakteriler üzerindeki etkilerinin yanında çeşitli antibiyotikler ve dezenfektanlar ile kombine edilerek tedavi edici ve koruyucu etkinliği yeni yapılacak çalışmalarla değerlendirilebilir.

Anahtar Sözcükler: Resveratrol, antibakteriyel ajanlar, antifungal ajanlar, hemoliz.

\title{
In Vitro Evaluation of the Antibacterial and Antifungal Effects of Resveratrol on Staphylococcus Aureus, Escherichia Coli, Pseudomonas Aeruginosa and Candida Albicans
}

\begin{abstract}
Aim: Resveratrol was first isolated from the roots of the plant in the Melanthiaceae family in 1940 and is found in plants at high concentration especially in red grapes, peanuts, pineapples, berries, and blueberries. It has antioxidant, antifungal, antibacterial, anti-inflammatory, antiproliferative effects as well as is a natural polyphenol with various biochemical effects. In this study, it has been investigated whether resveratrol obtained from Polygonum Cuspidatum root has a reducing or inhibitory effect on some microbial and fungal human infections.

Method: In this study; Candida albicans, Escherichia coli, Pseudomonas aeruginosa and Staphylococcus aureus microorganisms were used. Each of the microorganisms used in this study was implanted on suitable media for their reproduction. Each microorganism was implanted in normal media without resveratrol as well as in medias containing resveratrol at 1/4 and $1 / 1$ dilution rates and incubated at a specific period for the growth of organisms.

Findings: At the end of the incubation period, beta hemolysis and reproduction of Staphylococcus aureus were detected in the resveratrol-free medium. Ability to make beta hemolysis in $5 \%$ sheep blood medium containing resveratrol with $1 / 1$ and $1 / 4$ dilution was lost and its growth was inhibited in Mueller Hinton medium containing resveratrol with $1 / 1$ and $1 / 4$ dilution. No change was observed in the growth of Escherichia coli, Pseudomonas aeruginosa and Candida albicans microorganisms in the media with (1/1 and 1/4 dilution) and without resveratrol.
\end{abstract}


Conclusion: In addition to the effects of resveratrol on gram-positive bacteria, its therapeutic and protective efficacy in combination with various antibiotics and disinfectants can be evaluated with new studies.

Keywords: Resveratrol, anti-bacterial agents, antifungal agents, hemolysis.

\section{Giriş}

Resveratrol, ilk olarak 1940 yılında Melanthiaceae (Dokuztepegiller) familyasında yer alan bitkinin köklerinden izole edilmiştir ${ }^{1}$. Bitkilerde özellikle kırmızı üzüm, yer fıstığı, ananas, dut ve yaban mersininde yüksek konsantrasyonda bulunmaktadır ${ }^{2}$. Resveratrol (3,5,4'-trihidroksistilben) antioksidan, antifungal, antibakteriyel, anti-inflamatuar, anti-proliferatif etkilerin yanında çeşitli biyokimyasal etkilere sahip doğal bir polifenoldür ${ }^{1}$. Yapılan bazı çalışmalarda resveratrolün çeşitli konsantrasyonlarının farklı bakteri ve mantarlar üzerinde çoğalmayı azaltıcı veya organizmayı öldürücü etkisi olduğu belirtilmektedir. ${ }^{3-12}$. Bazı çalışmalarda ise Candida türü üzerinde etkisi olmadığı belirtilmiştir ${ }^{13,14}$.

Bu çalışmada Polygonum Cuspidatum kökünden elde edilen resveratrolün yoğun bakım hastalarından üretilen Escherichia coli, Pseudomonas aeruginosa, Staphylococcus aureus gibi bakteriyel ve Candida albicans gibi fungal insan enfeksiyonları üzerindeki çoğalmayı azaltıcı veya durdurucu etkisi olup olmadığı in vitro olarak araştırılmıştır.

\section{Gereç ve Yöntem}

\section{Bakteriler ve Mantarlar}

Çalışmamızda kullanılan Escherichia coli, Pseudomonas aeruginosa, Staphylococcus aureus ve Candida albicans maddi kısıtlılıklar nedeniyle mikrobiyolojik çalışmalarda kullanılması önerilen lisanslı American Type Culture Collection (ATCC) suşlar yerine Yenibosna Özel Safa Hastanesi Mikrobiyoloji laboratuvarında rutin olarak yoğun bakım hastalarının klinik materyallerinden izole edilen suşlar kullanılmıştır.

\section{Besiyerlerinin Eldesi}

Çalışmada kullanılan besiyerleri (\%5 koyun kanlı agar, Eosin Methylen-blue Lactose 
Sucrose (EMB) agar, Mueller Hinton agar ve Sabouraud Dextroz agar) Premed Tibbi Ürünler Firması tarafından standart ve iki farklı konsantrasyonda resveratrol katkılı (100 mg/L ve $400 \mathrm{mg} / \mathrm{L}$ ) olmak üzere hazırlanmıştır. Resveratrol katkı maddesi ABD menşeli Solgar Vitamin ve Sağlık Ürünleri firmasından temin edilmiştir. Bitkisel kapsüller havanda ezilerek ve 10 dakika vortekste tutularak hazırlanmakta olan besiyerlerine uygun oranlarda homojen olarak ilave edilmiştir. Resveratrol eklenmiş ve eklenmemiş besiyerleri etüvde $\left(35,5^{\circ} \mathrm{C}\right)$ en az bir gece kalite kontrol amaçlı boş olarak kontrole tabi tutulmuştur. Kalite kontrol numunelerinde beklendiği üzere herhangi bir üreme olmadığı gözlenmemiştir.

\section{Organizmaların Besiyerlerine Ekimi}

Candida albicans Sabouraud Dextrose ve \%5 koyun kanlı besiyerlerine, Escherichia coli \%5 koyun kanlı ve EMB besiyerlerine, Pseudomonas aeruginosa ve Staphylococcus aureus \%5 koyun kanlı ve Mueller Hinton besiyerlerine ekilmiştir. Her mikroorganizma ekimi için önceden \%5 koyun kanlı besiyerinde 2 gece inkübe edilmiş olan suşlarından 1-2 koloni alınarak serum fizyolojik içinde süspansiyon hazırlanmıştır. $\mathrm{Bu}$ süspansiyondan 0,05 ml'lik öze yardımı ile örnek alınarak seyreltme yöntemi ile uygun besiyerlerine ekim yapılmıştır.

\section{Besiyerlerindeki Üremenin Değerlendirilmesi}

Çalışmamızda söz konusu kandida cinsi mayalar için -literatür ile uygun biçimde- 5 günlük, bakteri kültürü için ise bakterilerin mantarlara kıyasla hızlı üremesi nedeniyle 3 günlük inkübasyon süresi öngörülmüştür. Ancak çalışmamızda gerek kandida gerek bakteriler bir gecelik inkübasyon sonrası üreme göstermiştir. Bu nedenle kandida üremesi için 5 gün bakterilerin üremeleri için 3 gün beklemeye gerek kalmamıştır. Kültür sonucu ‘Üreme Var’ veya ‘Üreme Yok’ şeklinde değerlendirilmiştir. Öte yandan Staphylococcus aureus'un Mueller Hinton besiyerinde üremesinin olmadiğına karar vermek için 3 gün beklenmiştir. Candida albicans için Sabouraud Dextrose ve \%5 koyun kanlı besiyerlerinde, Escherichia coli için koyun kanlı ve EMB besiyerlerinde, Pseudomonas aeruginosa ve Staphylococcus aureus için \%5 koyun kanlı ve Mueller Hinton besiyerlerinde belirtilen sürelerde bekletilmiştir. Gözle görülür üreme aranmış ve fotoğraflanmiştır. 


\section{Bulgular}

\section{Candida Albicans}

İnkübasyon işlemi sonunda $100 \mathrm{mg} / \mathrm{L}$ ve $400 \mathrm{mg} / \mathrm{L}$ konsantrasyonlu resveratrol katkılı \%5 koyun kanlı ve Sabouraud Desxtrose besiyerlerinde üremede herhangi bir inhibisyona rastlanmamıştır. 1:1 ve 1:4 dilüsyonlu resveratrolün Candida albicans üzerine in vitro olarak (\%5 koyun kanlı agar ve Sabouraud Dextrose besiyerinde) inhibe edici etkisinin olmadığı gözlenmiştir (Tablo 1).

\section{Escherichia Coli}

İnkübasyon işlemi sonunda $100 \mathrm{mg} / \mathrm{L}$ ve $400 \mathrm{mg} / \mathrm{L}$ konsantrasyonlu resveratrol katkılı \%5 koyun kanlı ve EMB besiyerlerinde üremede herhangi bir inhibisyona rastlanmamıştır. 1:1 ve 1:4 dilüsyonlu resveratrolün Escherichia coli üzerine in vitro olarak (\%5 koyun kanlı agar ve EMB besiyerinde) inhibe edici etkisinin olmadığı gözlenmiştir (Tablo 1).

\section{Pseudomonas Aeruginosa}

İnkübasyon işlemi sonunda $100 \mathrm{mg} / \mathrm{L}$ ve $400 \mathrm{mg} / \mathrm{L}$ konsantrasyonlu resveratrol katkılı \%5 koyun kanlı ve Mueller Hinton besiyerlerinde üremede herhangi bir inhibisyona rastlanmamıştır. 1:1 ve 1:4 dilüsyonlu resveratrolün Pseudomonas aeruginosa üzerine in vitro olarak (\%5 koyun kanlı agar ve Mueller Hinton besiyerinde) inhibe edici etkisinin olmadığg gözlenmiştir (Tablo 1).

\section{Staphylococcus Aureus}

Stahylococus aureus \%5 koyun kanlı besiyerinde tipik olarak beta hemolize sebep olan bir bakteridir. Beta hemoliz; kanlı agarda bir bakteri kolonisinin gelişmesi sırasında etrafındaki rengin tamamen açılmasıdır. Beta hemolize yol açan bakteriyel faktörler Staphylococcus aureus'un insanda hastalık yapma özelliği ile ilişkilidir.

Stahylococus aureus'un resveratrol katkılı olmayan \%5 koyun kanlı agarda inkübasyon işlemi sonunda beta hemoliz yaptığı gözlenmiştir (Şekil 1). $100 \mathrm{mg} / \mathrm{L}$ ve $400 \mathrm{mg} / \mathrm{L}$ konsantrasyonlu resveratrol katkılı \%5 koyun kanlı besiyerinde ise Staphylococcus aureus'un beta hemoliz oluşturmadı̆̆ gözlenmiştir (Şekil 2,3). 1:1 ve 1:4 dilusyonlu resveratrol içeren besiyerlerinde Staphylococcus aureus'un beta hemoliz yapma 
yeteneği kaybolmuştur. Olası tesadüfi durumu önlemek amacıyla ekim işlemi 1:1 ve 1:4 dilüsyonlu resveratrol içeren \%5 koyun kanlı besiyerinde 3 kez tekrar edilmiştir. Hepsinde aynı sonuç gözlenmiştir.

Resveratrol içermeyen Mueller Hinton besiyerinde Staphylococcus aureus üremesi izlenmiştir (Şekil 4). $100 \mathrm{mg} / \mathrm{L}$ ve $400 \mathrm{mg} / \mathrm{L}$ konsantrasyonlu resveratrol katkılı Mueller Hinton besiyerlerinde ise inkübasyon işlemi sonunda Staphylococcus aureus üremesinin tamamen inhibe olduğu görülmüştür (Şekil 5,6). Olası tesadüfi durumu önlemek amacıyla ekim işlemi 1:1 ve 1:4 dilüsyonlu resveratrol içeren Mueller Hinton besiyerinde 3 kez tekrar edilmiştir. Hepsinde aynı sonuç gözlenmiştir.

Şekil 1: Stahylococcus aureus'un resveratrol katkılı olmayan \%5 koyun kanlı besiyerinde arkadan ışık kaynağı tutulduğundaki beta hemolizi görülmektedir.

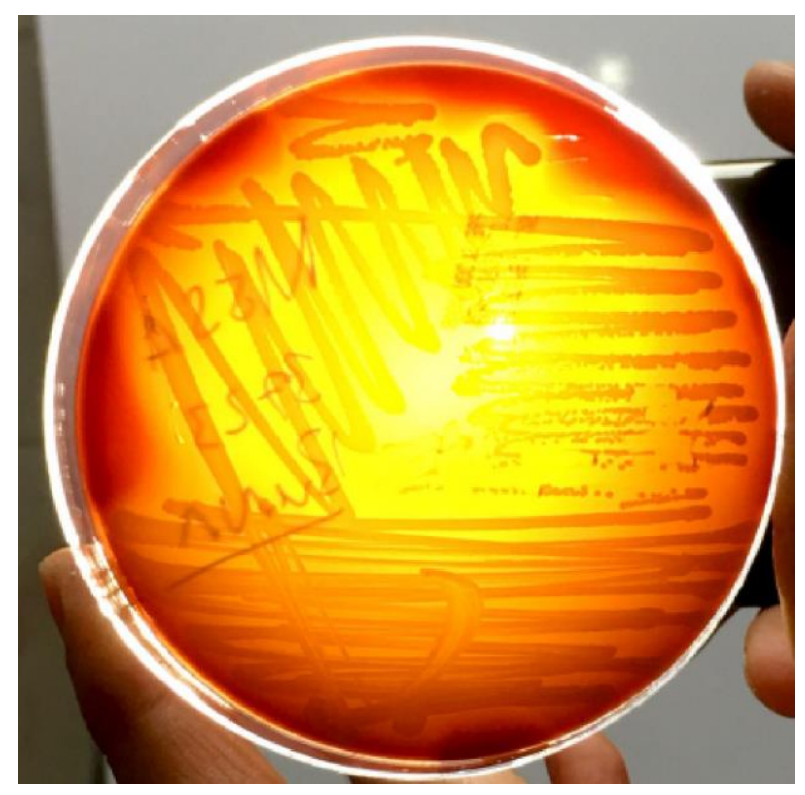


Şekil 2: $100 \mathrm{mg} / \mathrm{L}$ konsantrasyonlu resveratrol katkılı \%5 koyun kanlı besiyerinde Staphylococcus aureus'un arkadan ışık kaynağı tutulduğunda beta hemoliz oluşturmadığı görülmektedir.

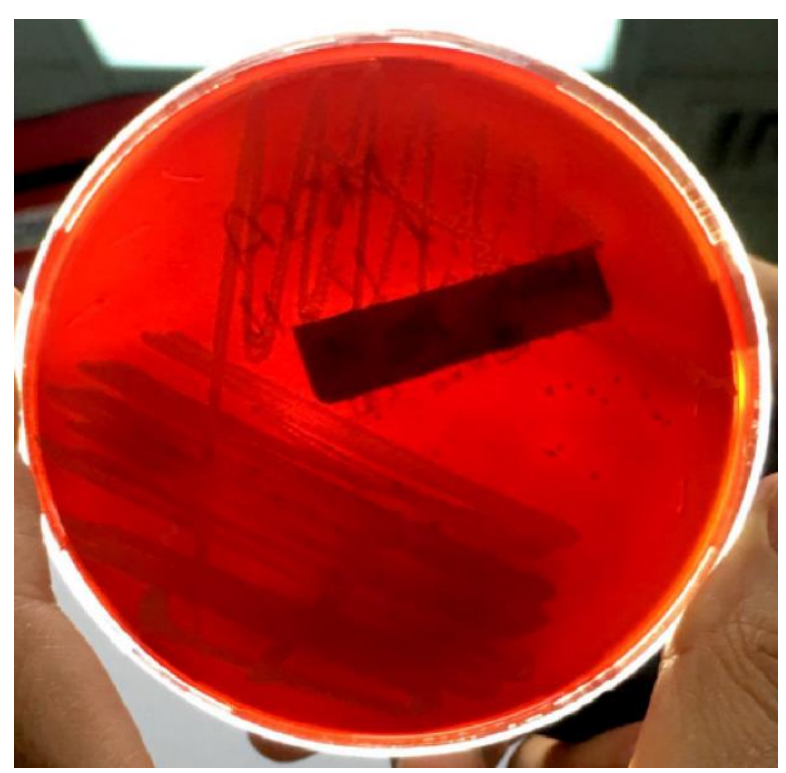

Şekil 3: $400 \mathrm{mg} / \mathrm{L}$ konsantrasyonlu resveratrol katkılı \%5 koyun kanlı besiyerinde Staphylococcus aureus'un arkadan ışık kaynağı tutulduğunda beta hemoliz oluşturmadığı görülmektedir.

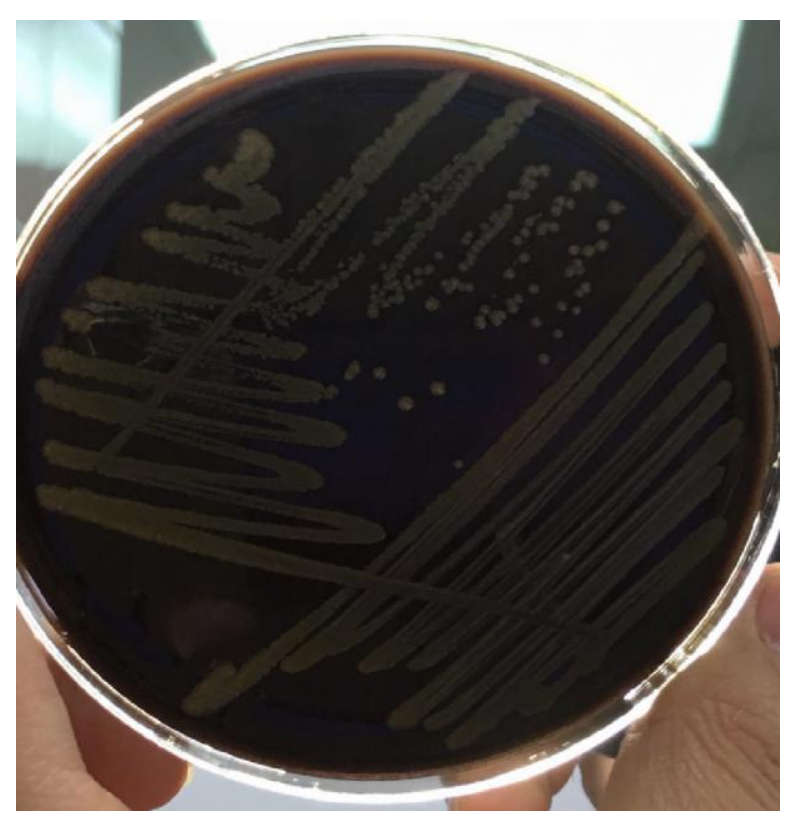


Şekil 4: Resveratrol içermeyen Mueller Hinton besiyerinde Stahylococcus aureus üremesi görülmektedir.

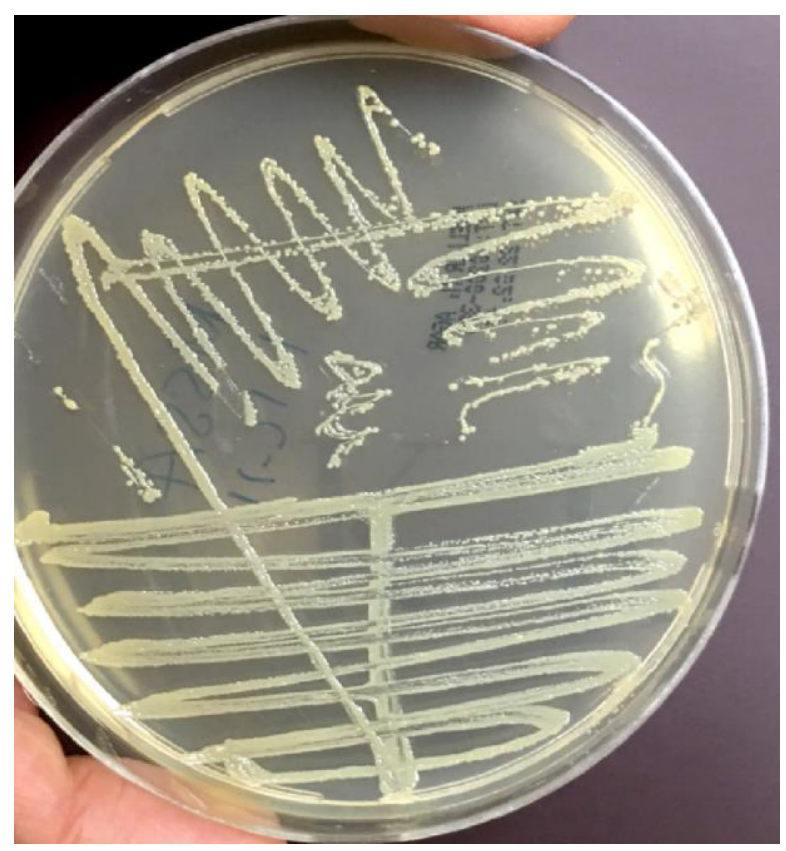

Şekil 5: $100 \mathrm{mg} / \mathrm{L}$ konsantrasyonlu resveratrol katkılı Mueller Hinton besiyerlerinde inkübasyon işlemi sonunda Staphylococcus aureus üremesinin tamamen inhibe olduğu görülmektedir.

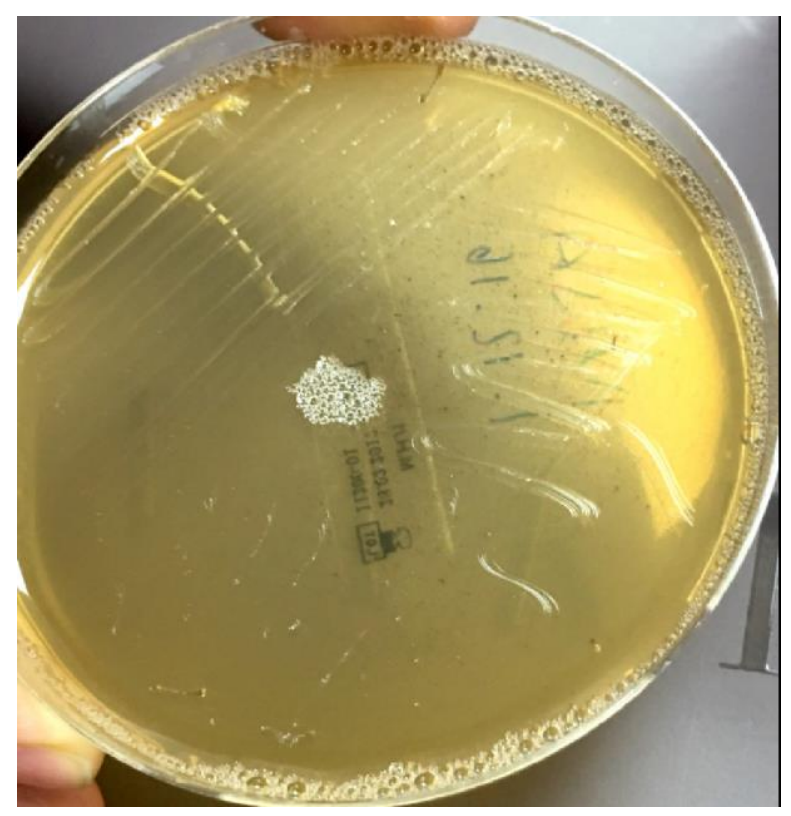


Şekil 6: $400 \mathrm{mg} / \mathrm{L}$ konsantrasyonlu resveratrol katkılı Mueller Hinton besiyerlerinde inkübasyon işlemi sonunda Staphylococcus aureus üremesinin tamamen inhibe olduğu görülmektedir.

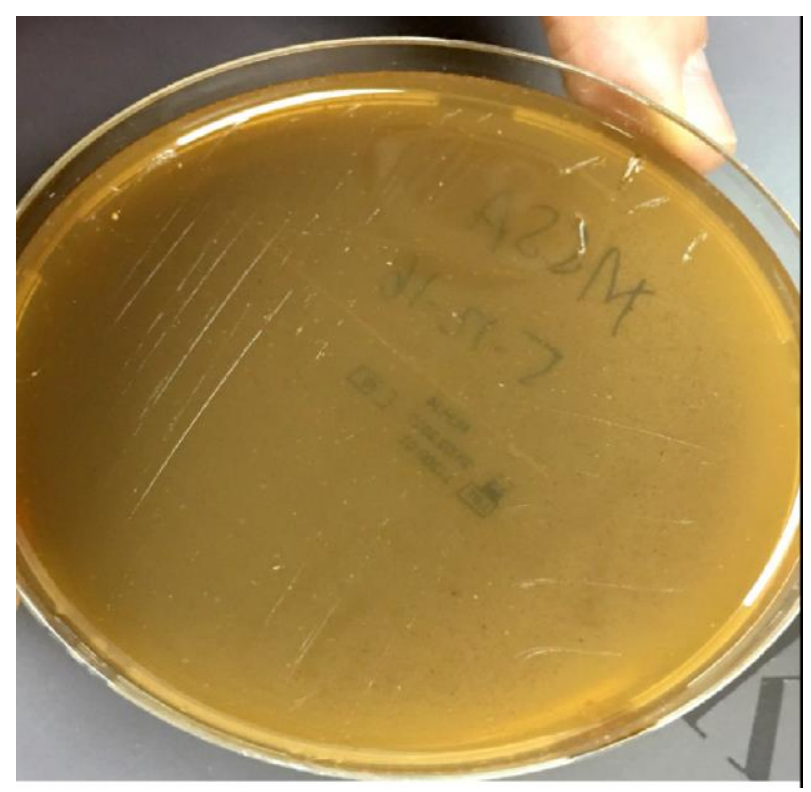

Tablo 1: Besiyerleri, besiyerlerine eklenen resveratrol oranları ve resveratrolün mikroorganizmaların büyümeleri üzerine etkileri

\begin{tabular}{|c|c|c|c|c|c|c|c|c|c|c|c|}
\hline Mikroorganizma & $\begin{array}{l}\text { Staphylococcus } \\
\text { aureus }\end{array}$ & Escher & ichia co & & & & $\begin{array}{l}\text { Pseud } \\
\text { aerugi }\end{array}$ & mona & & $\begin{array}{l}\text { Candi } \\
\text { albica }\end{array}$ & \\
\hline Besiyeri & R yok & $1 / 4 \mathrm{R}$ & $1 / 1 \mathrm{R}$ & R yok & $1 / 4 \mathrm{R}$ & $1 / 1 \mathrm{R}$ & R yok & $1 / 4 \mathrm{R}$ & $1 / 1 \mathrm{R}$ & R yok & $1 / 4 \mathrm{R}$ \\
\hline$\% 5 \mathrm{KK}$ & + & $\begin{array}{r}+ \\
\mathrm{BH}(-)\end{array}$ & $\begin{array}{r}+ \\
\mathrm{BH}(-)\end{array}$ & + & + & + & + & + & + & + & + \\
\hline EMB & & & & + & + & + & & & & & \\
\hline SD & & & & & & & & & & + & + \\
\hline MH & + & - & - & & & & + & + & + & & \\
\hline
\end{tabular}

[(+) üreme oldu, (-) üremede tam inhibisyon, (R) resveratrol, (KK) koyun kanlı, (EMB) Eosin Methylenblue Lactose Sucrose, (SD) Sabouraud Dextrose, (MH) Mueller Hinton, (BH) Beta Hemoliz] 


\section{Tartışma}

Çalışmamızda $100 \mathrm{mg} / \mathrm{L}$ ve $400 \mathrm{mg} / \mathrm{L}$ konsantrasyonlarında resveratrol eklenmiş besiyerlerinde resveratrolün Candida albicans, Escherichia coli ve Pseudomonas aeruginosa üremesi üzerine inhibe edici etkisi olmamıştır.

1:4 ve 1:1 dilüsyonlu resveratrol eklenmiş \%5 koyun kanlı besiyerlerinde resveratrolün Staphylococcus aureus beta hemolizini inhibe ettiği ancak üreme üzerine bir etkisi olmadığı izlenmiştir. 1:1 ve 1:4 oranında resveratrol eklenmiş Mueller Hinton besiyerlerinde ise üremenin inhibe olduğu gözlemlenmiştir.

Bizim ulaştı̆̆ımız sonuçlarla farklılıklar ve benzerlikler gösteren başka çalışmalar mevcuttur. Staphylococcus aureus ve Pseudomonas aeruginosa insan cildinde en sik bulunan patojenlerdendir. Staphylococcus aureus folikülit, impetigo, fronkül ve selülit gibi önemli cilt hastalıklarına neden olmaktadır. Pseudomonas aeruginosa ise yanık nedeniyle oluşan yaraları enfekte etmektedir. Marion Man-Ying Chan'ın (2001) yaptığı çalışmada çalışmamızda kullanılan konsantrasyonlara benzer oranlarda $(2-512 \mathrm{mg} / \mathrm{mL})$ kullanılan resveratrolün bu bakteriler üzerine antimikrobiyal etkinliği gösterilememiştir. Bu çalışmada bizim çalışmamızdan farklı olarak ekimler Tripticase soy agara yapılmıştır.

Çikolata besiyerinde yapılan bir başka çalışmada resveratrolün antibakteriyel etkinliğinin Neisseria meningitidis ve Neisseria gonorrhoeae bakterilerine spesifik olduğu, Escherichia coli, Staphylococcus aureus, Streptococcus pyogenes, Pseudomonas aeruginosa veya Candida albicans üremesi üzerinde en yüksek konsantrasyonda dahi etkisinin olmadığı gösterilmiştir5. Fakat bu çalışmada kullanılan en yüksek resveratrol konsantrasyon düzeyi (200 $\mathrm{mg} / \mathrm{L})$ bizim çalışmamızda kullanılanın en yüksek konsantrasyonun yarısıdır. Bu çalışmadan farklı olarak bizim çalışmamızda $100 \mathrm{mg} / \mathrm{L}$ konsantrasyonlu resveratrol içeren Mueller Hinton besiyerinde dahi Staphylococcus aureus üremesi tamamen inhibe olmuştur.

Bir başka çalışmada resveratrolle birlikte luteolin, quercetin, scutellarin, apigenin, chlorogenic asit gibi diğer bitki polifenollerinin metisillin dirençli Staphylococcus aureus (MRSA) üzerine belirgin antimikrobiyal etkisinin olduğu gösterilmiştir ${ }^{16}$. Ayrıca in vitro olarak ilaçlarla kombine edildiklerinde sinerjistik ve aditif etkilerinin olduğu antagonistik etkilerinin olmadığı bildirilmiştir. 
Staphylococcus aureus'un çalışmamızdaki tek gram pozitif bakteri olması ve resveratrolün çalıştığımız diğer mikroorganizmalar içerisinde sadece bu bakterinin üremesini inhibe etmesi ve patojenitesinden sorumlu beta hemolizi önlemesi diğer gram pozitif bakteriler üzerinde de etkili olabileceğini düşündürmektedir. Bunun çok sayıda gram pozitif bakteri içeren çalışmalar yapılarak değerlendirilmesi gereklidir.

\section{Sonuç}

$\mathrm{Bu}$ araştırmadan elde edilen bulgular Staphylococcus aureus'a bağlı enfeksiyonlarda resveratrolün tedavi amaçlı kullanılabileceğini düşündürmektedir. Bunun yanında yapılacak yeni in vivo çalışmalarda resveratrolün çeşitli antibiyotikler ve dezenfektanlar ile kombine edilerek tedavi edici ve koruyucu etkinliği araştırılabilir.

\section{KAYNAKLAR}

1. Kılınçlı, A. Resveratrolün Hücresel Yaşlanmanın İndüklenmesi ve Sirtüinlerin Aktivasyonunda Rolünün İnsan Dermal Fibroblastlarında Araştırılması. [yüksek lisans tezi]. Aydın, Türkiye: Adnan Menderes Üniversitesi Fen Bilimleri Enstitüsü; 2013.

2. Aggarwal BB, Bhardwaj A, Aggarwal RS, Seeram NP, Shishodia S, Takada Y. Role of resveratrol in prevention and therapy of cancer: preclinical and clinical studies. Anticancer Research. 2004;24:2783-2840.

3. Caruso F, Mendoza L, Castro P, et al. Antifungal activity of resveratrol against Botrytis cinerea is improved using 2-Furyl derivatives. PLOS ONE. 2011;6(10):e25421. doi: 10.1371/journal.pone.0025421.

4. Cirano FR, Casarin RCV, Ribeiro FV, et al. Effect of resveratrol on periodontal pathogens during experimental periodontitis in rats. Braz Oral Res. 2016;30(1):1-7. doi: 10.1590/1807-3107BOR-2016.vol30.0128.

5. Ferreira C, Soares DC, Nascimento MTC, et al. Resveratrol is active against Leishmania amazonensis: In vitro effect of its association with amphotericin B. Antimicrobial Agents and Chemotherapy. 2014;58(10):6197-6208. doi: 10.1128/AAC.ooo93-14.

6. Houillé B, Papon N, Boudesocque L, et al. Antifungal activity of resveratrol derivatives against Candida species. Journal of Natural Products. 2014;77(7):16581662. doi: 10.1021/np5002576. 
7. Hwang D, Lim YH. Resveratrol antibacterial activity against Escherichia coli is mediated by Z-ring formation inhibition via suppression of FtsZ expression. Scientific Reports. 2015;5:(10029):1-10. doi: 10.1038/srep10029.

8. Jung HJ, Seu YB, Lee DG. Candicidal action of resveratrol isolated from grapes on human pathogenic yeast C. Albicans. Journal of Microbiology and Biotechnology. 2007;17(8):1324-1329.

9. Lee JH, Kim YG, Ryu SH, Cho MH, Lee J. Resveratrol oligomers inhibit biofilm formation of escherichia coli $\mathrm{O}_{157} \mathrm{H} 7$ and pseudomonas aeruginosa. Journal of Natural Products. 2014;77(1):168-172. doi: 10.1021/np400756g.

10. Lee J, Lee DG. Novel antifungal mechanism of resveratrol: apoptosis inducer in Candida albicans. Current Microbiology. 2015;70(3):383-389. doi: 10.1007/so0284014-0734-1.

11. Nacrowki EM, Bedell HW, Humphreys TL. Resveratrol is cidal to both classes of Haemophilus ducreyi. International Journal of Antimicrobial Agents. 2013;41:477479. doi: 10.1016/j.ijantimicag.2013.02.008.

12. Taylor EJM, Yu Y, Champer J, Kim J. Resveratrol demonstrates antimicrobial effects against Propionibacterium acnes in vitro. Dermatology and Therapy. 2014;4(2):249-257. doi: 10.1007/s13555-014-0063-0.

13. Collado-Gonzalez M, Guirao-Abad JP, Sanchez-Fresneda R, Belchi-Navarro S, Argüelles JC. Resveratrol lacks antifungal activity against Candida Albicans. World $J$ Microbiol Biotechnol. 2012;28(6):2441-2446. doi: 10.1007/s11274-012-1042-1.

14. Weber K, Schulz B, Ruhnke M. Resveratrol and its antifungal activity against Candida species. Mycoses. 2011;54(1):30-33. doi: 10.1111/j.1439-0507.2009.01763.x.

15. Docherty JJ, Fu MM, Tsai M. Resveratrol selectively inhibits Neisseria gonorrhoeae and Neisseria meningitidis. J Antimicrob Chemoter. 2011;47:243-244. doi: 10.1093/jac/47.2.243.

16. Su Y, Ma L, Wen Y, Wang H, Zhang S. Studies of the in vitro antibacterial activities of several polyphenols against clinical ısolates of methicillin-resistant staphylococcus aureus. Molecules. 2014;19:12630-12639. doi: 10.3390/molecules190812630. 